\title{
Cuerpo y ritual como proceso de intervención. Análisis crítico de la obra de Rosario García Crespo
}

\author{
Dra. Inmaculada Abarca Martínez \\ Universidad de Murcia \\ Facultad de Bellas Artes, Área de Escultura. \\ Correo: iabarca@um.es \\ Recibido para su publicación: 30 de agosto de 2015 \\ Aprobado: 01 de octubre de 2015
}

\section{Introducción}

En la actualidad, los numerosos creadores que vinculan sus prácticas artísticas a la Naturaleza tienen en común la idea ecológico-mística de ésta, como una entidad sagrada que necesita de nuestra atención y de nuestro cuidado. Debemos entender que si bien, sus obras se circunscriben al ámbito contemporáneo, también se emplazan en la encrucijada que comunica al hombre con el cuerpo mítico de las religiones, sean éstas las que sean. Lo que aquí llamamos ritual no está en relación directa con ninguno de los hábitos religiosos que en la actualidad se puedan practicar. La mitología individual que cada uno de estos artistas desarrolla tiene que ver tanto con las cualidades intrínsecas de los materiales utilizados y las acciones llevadas a cabo, como con la posibilidad de comunicación y por lo tanto, de transmisión de los sentimientos experimentados. En este sentido, no existe un ritual mágico sino un uso del sentido común, aquel que llama al cuidado de todo aquello que nos rodea y de lo que éticamente, debemos sentirnos responsables, así como parte integrante.

En el ámbito social y en cuanto a las prácticas artísticas se refiere, estas circunstancias se manifiestan en un desplazamiento de la atención hacia entornos menos explorados y explotados por el hombre como bosques o espacios naturales. En un entorno urbano son los jardines y parques públicos los que funcionan como escenario para declaraciones de índole interactiva con el público potencial. En todos los casos, la llamada está apuntando no sólo a la preservación, sino al cuerpo de lo social-humano del cual forma parte cada una de nuestras individualidades. De esta manera podemos apreciar que la Naturaleza aún y en el contexto polisémico que este concepto nos transmite, es un camino que, no por ampliamente recorrido por el hombre, ha perdido su capacidad de sorprendernos. En la actualidad, como actores de los cambios que estamos produciendo en el planeta, el arte se replantea su capacidad de interferir en contextos más amplios que el entorno cerrado de un taller, las galerías o los museos.

\section{Discusión}

No cabe duda de que cada una de las acciones desarrolladas por los artistas involucra un más allá que la mera expresión estética y con este compromiso, muchos de los artistas exploran no sólo la percepción de la Naturaleza como ente físico y social sino con la perspectiva intimista de un crecimiento personal. De entre los planteamientos constatados por este tipo de artistas podemos observar tipos de procedimientos artísticos que conllevan el andar como práctica artística. Esta acción, como hábito, no es específicamente contemporánea. Desde tiempos inmemoriales la trashumancia nómada está inscrita en nuestra historia como el arquetipo de cualquier recorrido. Éstos se originan en las interminables batidas de caza del Paleolítico cuyos significados simbólicos fueron traducidos por los egipcios por medio del ka, el símbolo del eterno errar. El errar primitivo ha perdurado a través de las religiones -el recorrido en tanto que mito- $y$ en las formas literarias -en tanto que narración- transformándose de esta manera en recorrido sagrado, danza, peregrinación o procesión.

En este sentido, la obra de la artista mexicana Rosario García Crespo (México, D.F., 1953), se ha caracterizado por manifestar en lo procesual de sus recorridos la base de su encuentro con la Naturaleza. La artista usa el caminar como parte de un proceso o procedimiento para realizar su obra. Asimismo, en el camino y en los lugares que va encontrando, se vale de una serie de acciones programadas o no, en comunión con la Naturaleza. Aunque a lo largo de su trayectoria ha andado en diferentes entornos, tanto naturales como urbanos, en sus más recientes trabajos se ha decantado por un viaje hacia su propio yo interior. La artista rescata en su proceder, en la misma línea del poeta 
Marcel Réja (1907), las palabras del loco: "Viajo para conocer mi geografía" (Benjamin, 2004, p. 421) asumiéndose como flâneur contemporáneo y utilizando la escritura con su propio cuerpo, para describir el recorrido y la recreación de símbolos en el paisaje, así como para descifrar en este mismo proceso, la esencia de sí misma y de su propia obra.

Sirviéndonos como directriz de la investigación realizada por Careri, podemos acercarnos a la comprensión de la obra de esta artista. El autor más que considerar la acción de andar como una herramienta crítica, la entiende como una manera obvia de mirar el paisaje. Para explicar su teoría, traza un recorrido crítico por la historia de la humanidad, desde la trashumancia de los primeros cazadores recolectores y la colocación de los menhires, pasando por Egipto y Grecia Antigua, hasta los artistas del Land Art, y de esta forma Careri (2003) apunta,

Hemos escogido el recorrido como una forma de expresión que subraya un lugar trazando físicamente una línea. El hecho de atravesar, instrumento de conocimiento fenomenológico y de interpretación simbólica del territorio, es una forma de lectura psicogeográfica del territorio comparable al walkabout de los aborígenes australianos (pp. 10-17).

Careri señala la idea de que en todas las épocas el andar ha producido arquitectura y paisaje y que esta práctica, olvidada por los arquitectos, ha sido reactivada por poetas, artistas y filósofos, quienes han sido capaces de mirar de manera diferente en los intersticios de la realidad, generando mediante esta reflexión, nuevas pautas de pensamiento. En esta línea, Careri acuña el término de Walkscapes para referirse al poder dinamizador del andar que pone en movimiento todo el cuerpo, el individual pero también el social. Al andar se manifiestan con mayor claridad los lugares que transitamos, y no sólo éstos, sino los contornos indefinibles, los espacios intermedios y las fronteras interiores de la ciudad. Es una manera de trasformar el espíritu de quien a partir de ese momento ya sabe mirar, dilucidando con acierto los vacíos que nos son tan necesarios para una existencia plena. De hecho, el hombre, a través del andar como práctica natural, pero a la vez consciente, va construyendo el paisaje que lo rodea. Careri (2003) afirma: "El término recorrido se refiere al mismo tiempo al acto de atravesar (el recorrido como acción de andar), la línea que atraviesa el espacio (el recorrido como objeto arquitectónico) y el relato del espacio atravesado (el recorrido como estructura narrativa)" (p. 25).
Siguiendo a Careri, el errar primitivo, el desplazamiento humano o el recorrido en tanto que mito, ha permanecido vivo en la religión y en las prácticas literarias, transformándose en recorrido sagrado, peregrinación o procesión. En la actualidad, se podría trazar una historia del andar como forma de intervención urbana. En paralelo, dentro de la historia del arte, Careri marca tres momentos fundamentales en la historia del siglo XX en donde podemos seguir la importancia y el significado de la acción de andar. Estos tres puntos de inflexión son la transición del Dadaísmo al Surrealismo (1921-1924), el paso de la Internacional Letrista a la Internacional Situacionista (1956-1957) con la Teoría de la deriva y la del Minimalismo al Land Art (1966-1967).

Estos tres períodos nos permiten comprender la vivencia urbana de las diferentes formas de entender la ciudad. De esta forma, el recorrido se configura como una forma estética disponible tanto para la arquitectura como para el paisaje, el andar como un instrumento estético es capaz de describir y de modificar aquellos espacios urbanos que deberían comprenderse y llenarse más que de cosas, de significados. La reflexión de Careri nos conduce a entender el andar como una forma estética que, habiendo alcanzado el estatuto de disciplina autónoma permite considerar el vagabundeo o el errar como un valor más allá del error. La revalorización del recorrido durante el siglo XX se originó en el terreno de la literatura con Tristán Tzara, André Bretón y Guy Debord. Posteriormente en el campo de la escultura fueron Carl André, Richard Long y Robert Smithson quienes rescataron el término y la acción de andar, del camino hacia el anti-arte y el absurdo, al que los escritores lo habían conducido.

Enlazando con el significado del recorrido aportado por Careri, y enfocándonos en la obra de García Crespo, podemos observar que el concepto de recorrido, fundamental para esta artista, se centra en el cuerpo, el mundo vegetal y la escritura. De sus primeros recorridos en ciudades, la artista transfiere sus acciones a los grandes recorridos por los bosques. La génesis de este trabajo puede ubicarse en la exposición Caminata (1996) que Rosario realiza en el Museo Carrillo Gil (México, D.F.). A través de sus obras percibimos la idea de recorrido ampliada con otra faceta del mismo: el caminar como proceso de transformación interior. La artista al andar, articula una serie de relatos conformados por los recuerdos, signos y símbolos encontrados en el camino. Se trata del recorrido o viaje como herramienta de conocimiento interior. Así, los viajes que emprende esta 
artista nos remiten a Erich J. Leed, quien reflexiona sobre las relaciones que vinculan las palabras viaje, experiencia y peligro para evidenciar cómo en el origen del viaje late fundamentalmente, el deseo de mutación existencial:

Viajar es la expiación de una culpa, una iniciación, un acrecentamiento cultural, una experiencia: La raíz indoeuropea de la palabra experiencia es per, que ha sido interpretada como intentar, poner a prueba, arriesgar, unas connotaciones que persisten en la palabra peligro [...]. Esta concepción de la experiencia en tanto que cimiento, en tanto que paso a través de una forma de acción que mide las verdaderas dimensiones y la verdadera naturaleza de la persona o del objeto que lo emprende, describe también la concepción más antigua de los efectos del viaje sobre el viajero. Muchos de los significados secundarios de per se refieren explícitamente al movimiento: atravesar un espacio, alcanzar un objetivo, ir hacia fuera [...]. Una de las palabras alemanas que significan experiencia, Erfahrung, proviene del alto alemán antiguo, irfaran: viajar, salir, atravesar o vagar. La idea profundamente arraigada según la cual el viaje es una experiencia que pone a prueba y perfecciona el carácter del viajero aparece claramente en el adjetivo alemán bewandert, que actualmente significa sagaz, experto o versado (Leed, 1991; Careri, 2003, p. 40).

En este sentido García Crespo nos hace partícipes de sus experiencias y retomando el concepto de peligro, la artista relata cómo en una de sus caminatas, pasaba sobre una tubería elevada -varios metros por encima del nivel del suelo- y sintió cómo esta se cimbraba. Estaba sin proponérselo poniendo en peligro su vida, pero logró, mediante la respiración y el autocontrol, recuperar el equilibrio y cruzar al otro extremo. De esta forma, la artista, siguiendo al filósofo y novelista alemán Ernst Jünger, en su libro La emboscadura, nos remite al sentir de que si bien el bosque es un hábitat abrigado, es también la "morada de un peligro aniquilador (Jünger, 1988) " (García Crespo, 2002, p. 35) que nos ofrece en contrapartida la oportunidad de dialogar con nuestros propios miedos.

Ante esta experiencia solitaria del peligro, cabe destacar aquí que las imágenes que sugieren ideas de puentes y pasajes peligrosos son frecuentes en rituales y mitologías iniciáticas relacionadas con el autoconocimiento y la sabidu- ría absoluta. Simbólicamente, estos elementos equivalen a la idea de tránsito de un estadio del ser a otro, operando como una especie de "mutación oncológica" (Eliade, 2003, p. 132). Esta manera de entrar en contacto con el peligro es una forma, a la vez, de experimentar la sensación de "lo sublime" (Burke, 1997, p. 42), idea que simultáneamente se corresponde con la experiencia de magnificencia provocada por el espectáculo de la Naturaleza a la que García Crespo nos acerca.

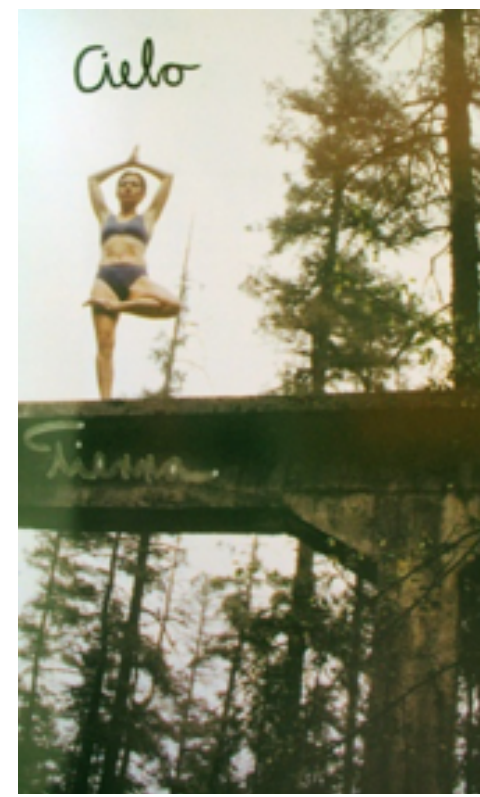

Fig $1 a$

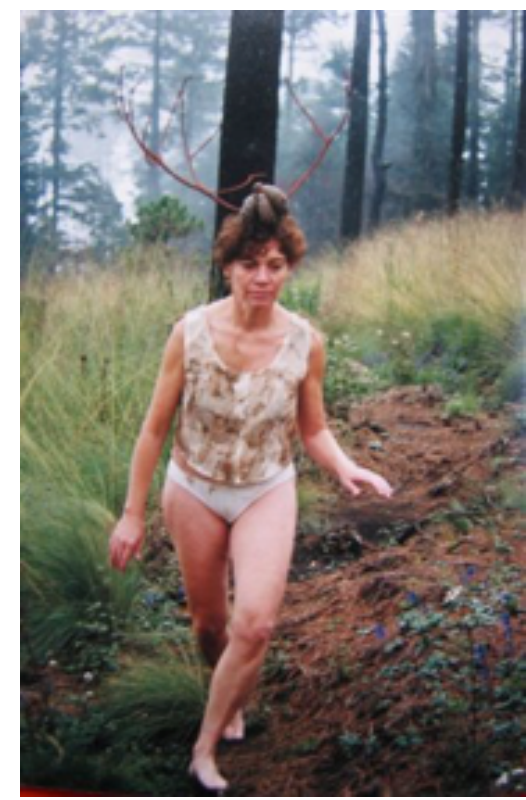




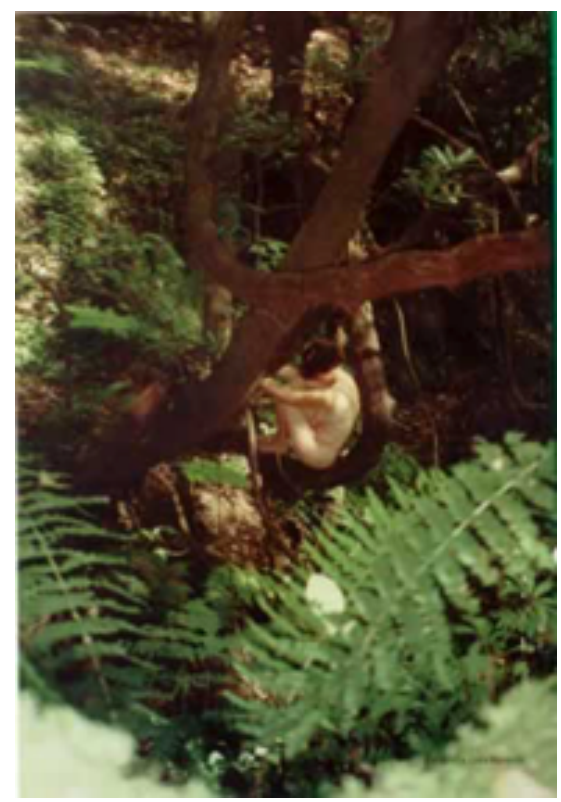

Fig 1c

En su libro Caminar para descifrar, la artista asume el andar como una forma nutritiva de existir: "Caminar es una manera de estar en el mundo, de pensar, de sentir diferente a la vida sedentaria" (García Crespo, 2002, p. 18). A través de este habitar el mundo y mediante ciertas disciplinas de las que hace uso, reconoce que ha sido capaz de moverse de acuerdo a los cambios de la vida. La artista registra fotográficamente sus acciones realizadas en varios lugares y durante largas temporadas, como por ejemplo en el Parque Nacional Desierto de los Leones, México (1997-1999) (Fig. 1a, 1b, 1c), Canadá (1999) o el Antiguo Camino a Chalma, Cuernavaca, México (2000-2001). En estas reiterativas caminatas percibe los cambios que sufre el paisaje debido a los efectos de las estaciones, a la acción del ser humano e incluso a los accidentes (incendios). La artista nos habla del cuidado y la concentración necesarios al caminar: en determinadas circunstancias, la caminata debe adecuarse a las irregularidades del terreno o debe volverse más lenta, apoyando cuidadosamente el talón o la punta de los pies, para no perder el equilibrio o para no lastimar el propio cuerpo, hay que, en definitiva, "encontrar otras formas de andar” (García Crespo, 2002, p. 19).

La búsqueda de equilibrio, entre otras, es una constante en sus acciones. Para estas ocasiones la atención se centra en los pies y la conexión de éstos con las raíces y las piedras. El proceso de registro fotográfico de las acciones da paso a la selección y composición de las mismas para lograr con ellas expresar el recorrido y la intención de las acciones. Como norma, el encuentro con los diferentes paisajes motiva la manera de intervenirlos. En opinión de Springer (2003), las fotografías de García Crespo son el registro de una meditación sobre la Naturaleza al interior de la misma "que abren una posibilidad para el habitante promedio de la urbe". Con ellas la artista nos presenta más que representaciones de la Naturaleza o del cuerpo femenino, una actitud que unifica vida y arte. Sus series de rituales ofrecen metáforas o alegorías de la presencia de la Naturaleza en el propio cuerpo, sea éste el de la artista o el nuestro.

Para García Crespo el bosque representa simbólicamente un lugar espiritual que nos ofrece la posibilidad de reencuentro con lo místico así como con todos aquellos mitos relacionados con él y con los seres mágicos que lo pueblan en el inconsciente cultural de todas las civilizaciones. En él, el individuo debe enfrentarse a ciertas pruebas de sobrevivencia física y espiritual con la ganancia de adquirir un mayor conocimiento sobre sí mismo. Al tratarse de un ambiente que a los habitantes de la ciudad ya no nos es natural -todo aquello inesperado nos obliga a generar nuevas formas de respuesta - la opción que la artista propone es:

[...] deshabituarnos de los pasos-ciudad, para aprender pasos-montaña, pasos-caída, pasos-equilibrio, pasos-calor, pasos-frío, pasos-humedad y pasos-sequedad. [...]. El regreso diario al bosque, pese a las caídas, los golpes, el cansancio y la exposición a cambios de temperatura, nos renueva. Para las personas que nacimos y hemos vivido en la ciudad, el gesto de irse al bosque es un gesto nuevo y, los gestos nuevos expresan una nueva forma de existencia. El gesto de irse al bosque tiene que ver con el gesto del acecho, el ser humano acecha la naturaleza porque personalmente no está en ella (García Crespo, 2002, pp. 36-37).

Por otra parte, las obras resultantes de estas acciones muestran además del acto de desplazarse y concebir el espacio de una manera diferente, una intersección mística con el mundo vegetal -se ha inclinado además de a la observación, a la recolección consciente de ciertos vegetales. Su relación con el espacio le permite escuchar y atender a 
lo que éste le va pidiendo para poder transitarlo. Estas acciones, se asemejan a una experiencia religiosa. El bosque aquí es el escenario de un acontecimiento: el cuerpo en el espacio. La reflexión en torno al tránsito de la experiencia religiosa -típica del ser humano primitivo- al recorrido como experiencia estética es referida por Careri (2003) de la siguiente manera:

La acción de atravesar el espacio nace de la necesidad natural de moverse con el fin de encontrar alimentos e informaciones imprescindibles para la propia supervivencia. Sin embargo, una vez satisfechas las exigencias primarias, el hecho de andar se convirtió en una acción simbólica que permitió que el hombre habitara el mundo. Al modificar los significados del espacio atravesado, el recorrido se convirtió en la primera acción estética que penetró en los territorios del caos (p. 20).

En este contexto, la artista genera acciones y utiliza simbolismos universalmente conocidos que devienen concepciones de lo sagrado. En relación a la noción de espacio sagrado, García Crespo, destaca la importancia particular en su obra del centro. Remitiéndonos de nuevo a las culturas primitivas y para explicitar su propia búsqueda y encuentro consigo misma, la artista concibe diferentes rituales para llegar al centro a través del viaje místico.

En la simbología del centro se considera que cualquier lugar puede significar el centro del universo por efecto de un ritual que conecte la tierra con el cielo. En diversas culturas se considera el símbolo de una montaña, de un árbol o de un pilar como el centro del mundo, como inserción del espacio sagrado en el espacio profano (García Crespo, 2002, pp. 8687).

En su obra aparecen mandalas o círculos mágicos trazados en el bosque en una acción sinérgica con el espacio y en pos del efecto benefactor de estos símbolos sobre la propia autora quien, se remite a Jung, para aclarar su uso.
Según Jung el símbolo mandálico no sólo es una expresión sino también tiene efecto benefactor sobre su autor. Las prácticas mágicas son proyecciones del alma que le facilitan a la persona la vivencia de su centro espiritual, donde puede reencontrarse con su alma y curarse (García Crespo, 2002, p. 88).

A través de la investigación sobre los mandalas y su significado, la artista desarrolla acciones, movimientos circulares, arriba-abajo, adentro-afuera en las que involucra la acción de su propio cuerpo, así como ciertos colores con los que identifica los conceptos sobre los que trabaja y quiere trasmitir. Los recorridos y la búsqueda mítica y mística a través de los bosques son aquí, una indagación, como en el caso de muchos otros artistas, en torno a la propia identidad -el yo como persona y el yo como artista- que encuentra en estos desplazamientos el espacio adecuado para efectuar una suerte de rituales, de toma de contacto con el medio natural. Es un viaje hacia el interior de uno mismo, una búsqueda de la propia naturaleza. Mediante los ritos que prescribe, la artista se funde con los elementos del paisaje, las piedras, la tierra, los árboles, las aguas, el paisaje en una fusión que resulta un acto de purificación y de investidura.

Así, la artista abraza un árbol cuyo tronco torcido crece en curva contradiciendo la verticalidad y, ante la carencia de corteza del mismo, ella adopta la postura junto con el árbol, en actitud de protección (Fig. 2). En otras ocasiones, caminando al lado de un río respira al ritmo de las corrientes acuáticas que se encuentra y realiza un rito de simulación en el que el agua fluye desde sus pies hasta sus brazos o utiliza su cuerpo, acostándose en forma de cruz sobre la sombra proyectada de un árbol, mimetizándose así con el paisaje al igual que ciertos animales que cambian de color adquiriendo el de su entorno.

La artista inicia su recorrido con un plan trazado y con una vestimenta diseñada por ella misma, de un determinado color. En el transcurso del viaje pasa de sentirse una ex- 

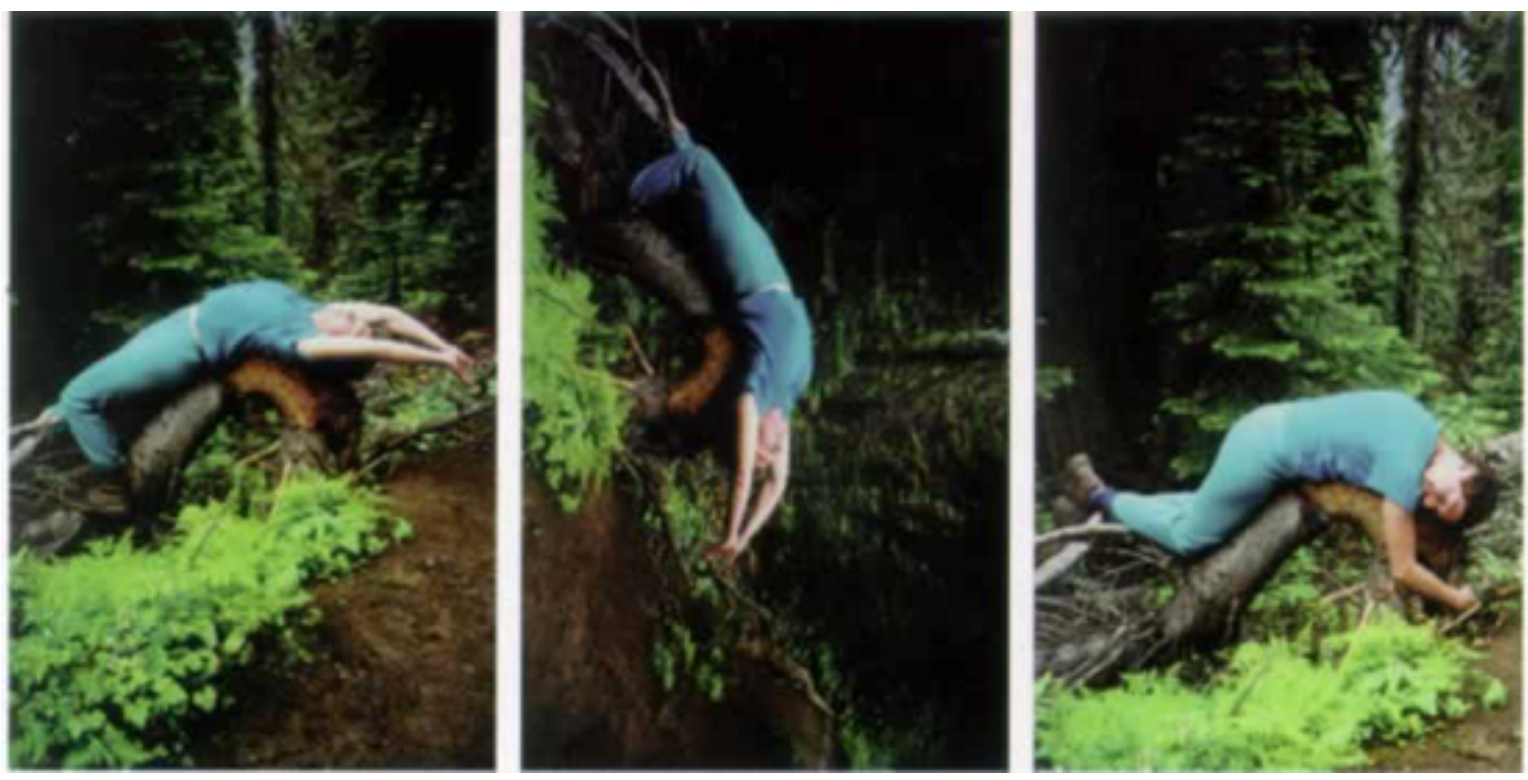

Fig 2

traña en el bosque, a incorporarse a él. Después de un día completo de caminar, con las hojas pegadas al cuerpo, las ramas a los cabellos, la tierra a los pies; de sudar, arrastrarse, mojarse y llenarse de lodo, finalmente se consuma la metamorfosis y se produce la alquimia de los colores. Se trata fundamentalmente de sensaciones físicas, pero también espirituales; tras este proceso, los pensamientos se desvanecen y ciertamente uno adquiere otra actitud frente a la vida, "ya no sentía humedad, olores a plantas y a tierra, sentía como vegetal y me movía como animal" (García Crespo, 2002, p. 45).

Este anhelo de Naturaleza y su utilización en las artes plásticas, está en consonancia con la sensación de pérdida que, a su vez, se corresponde directamente con nuestra vida cosmopolita. Para la artista, a partir de la década de los años sesenta, se verifica en el arte un retorno a los elementos, debido en particular a la problemática ambiental. Encontramos que en algunos de sus planteamientos García Crespo se acerca a la obra de otros artistas que han utilizado el caminar como práctica estética en México. Todos ellos se identifican con la idea de la acción de caminar como proceso creativo y como generador de nuevas visiones para la sociedad.

García Crespo, en consonancia con la lógica de Pierre Gassendi (1592-1655) -quien formulara la frase ambulo ergo sum (camino, luego existo) y, en contraposición a la de Descartes (1956-1650) cogito ergo sum (pienso, luego existo)- nos recuerda con su trabajo que los recorridos por el bosque permiten alcanzar una toma de conciencia que afecta directamente al actor de los mismos. El bosque se configura así, como una especie de santuario que permite acceder y consolidar el conocimiento. Esta idea relacionada con un cierto concepto de animismo, se apoya en las creencias de determinadas culturas antiguas para las cuales, los árboles -en ciertos rituales de paso y de cambio de las estaciones- son seres animados.

El culto a los árboles se fundamenta en la idea primitiva de que en ellos habitan ciertos espíritus y de que por lo tanto, todo en este mundo está animado. De hecho, esta idea pervive en diferentes comunidades primitivas y ha ido transformándose conservando a lo largo del tiempo, la estrecha relación entre plantas, árboles y humanos. En los cuentos populares, la vida de una persona está ligada a la de las plantas de tal manera que su marchitamiento o su prosperidad está "en relación directa con la del humano con la que se relaciona" (Frazer, 1986, p. 764). Entre ciertas culturas, esta idea se repite en la costumbre de conferir género a los árboles y en las cualidades que se les atribuye a éstos, al realizar ceremonias que vinculan árboles y personas. En esta misma línea y, mediante su capacidad creativa, la artista se configura en una especie de mediadora o chamán capaz de dialogar y establecer puentes entre las distintas fuerzas de la Naturaleza, con sus propiedades tanto beneficiosas como destructivas para el ser humano.

\section{Conclusión}

En resumen, las prácticas de García Crespo nos ofrecen una Naturaleza vista en relación al concepto estético-vitalista que sitúa al artista en la fusión entre arte/vida. Desde el planteamiento místico de la relación del hombre con su medio natural, el artista se establece como mediador/chamán quien a través de su búsqueda refleja una indagación sobre su propia identidad como artista y como persona. 
Este proceso conlleva la concepción de la Naturaleza como una entidad viva, Naturaleza igual a Ser vivo, en una especie de panteísmo que sustituye la religiosidad común por una ideología o conciencia ético-mística que más allá de cualquier simbolismo, se muestra también como la toma de conciencia de un compromiso ecológico.

En esta forma de pensamiento, la Naturaleza y sus procesos se convierten en sujeto fundamental que interviene en la obra en colaboración con el artista quien frente a la Naturaleza, se reserva un papel secundario. El aspecto procesual de estas prácticas se anclan en conceptos de espacio-tiempo similares a los de la Naturaleza misma, en consonancia con lo efímero de la misma. Por lo tanto, todos aquellos elementos capaces de transmitir las ideas de creación/destrucción y todos los procesos de transformación están involucrados, cuestionando la noción de permanencia e instaurando el de trascendencia. La lucha por la vida, por el equilibrio, por la armonía y la oscilación entre el crecimiento y la decadencia son vitales para establecer los ritmos entre vida y muerte, mismos que podemos observar en este tipo de obras.

${ }^{1}$ El artista mexicano-belga Francis Alÿs ha realizado recorridos erráticos arrastrando un artefacto: The Collector (1991), llevando unos Zapatos magnéticos (1994),

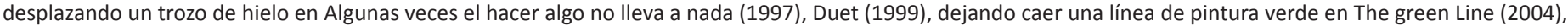

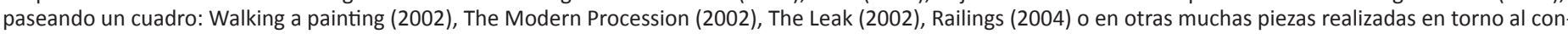
cepto de recorrido como generador de nuevas experiencias.

\section{Bibliografía}

Burke, E. (1997). Indagación filosófica sobre el origen de nuestras ideas acerca de lo sublime y de lo bello. Madrid: Tecnos.

Careri, F. (2003). Walkscapes. El andar como práctica estética/Walking as an aesthetic practice, Land \& Scape Series. Barcelona: Gustavo Gili.

Frazer, J.G. (1986). La rama dorada. Magia y religión. México, D.F.: Fondo de Cultura Económica.

García Crespo, R. (2002). Caminar para descifrar, México, D.F.: Consejo Nacional para la Cultura y las Artes.

Eliade, M. (2003). Lo sagrado y lo profano. p. 132. Barcelona: Paidós Orientalia.

Benjamin, W. (2004). El libro de los Pasajes, Edición de Rolf Tiedemann. Madrid: Akal.

Springer, J.M. (2003). "Un recorrido cifrado". Recuperado de http://www.replica21.com/archivo/articulos/g_h/163_gardea_gcrespo.html.

Autor: Ana Marcela García

Título: IMAGINERO

Técnica: Acrílico sobre lienzo

Medidas: $90 \times 130 \mathrm{~cm}$

Fecha: 2014

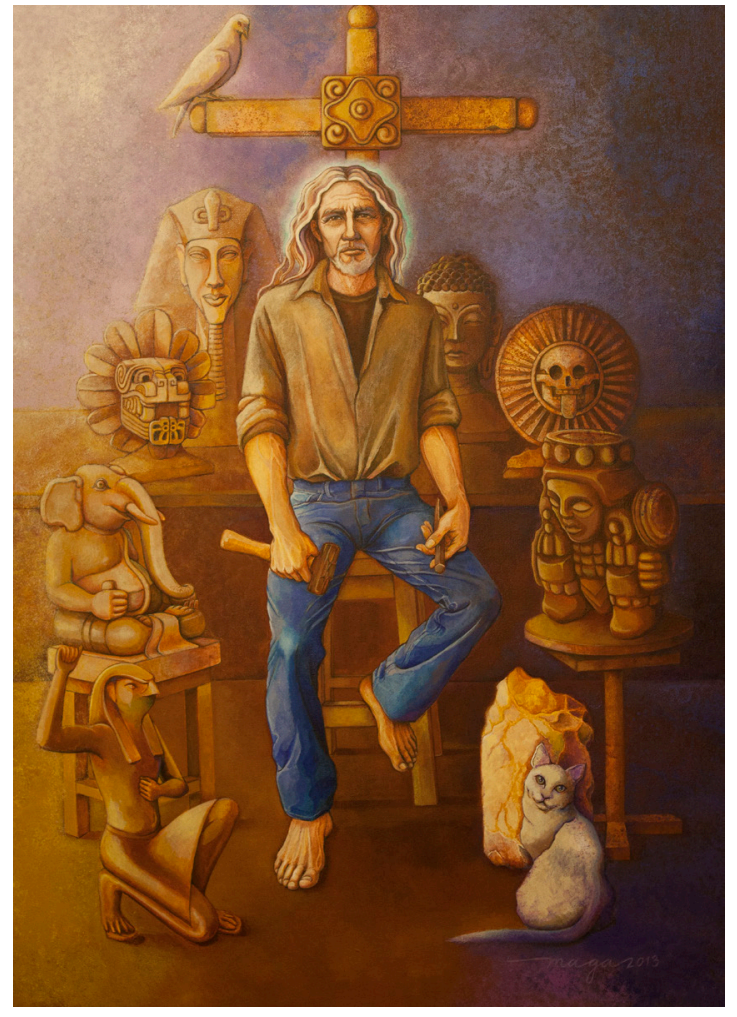

